\title{
Influence of dual-task on sit-to-stand-to-sit postural control in Parkinson's disease
}

Ângela Fernandes, Andreia S.P. Sousa, Joana Couras, Nuno Rocha, João Manuel R.S. Tavares

\begin{abstract}
Postural control deficits are the most disabling aspects of Parkinson's disease (PD), resulting in decreased mobility and functional independence. The aim of this study was to assess the postural control stability, revealed by variables based on the centre of pressure (CoP), in individuals with PD while performing a sit-tostand-to-sit sequence under single- and dual-task conditions.

An observational, analytical and cross-sectional study was performed. The sample consisted of 9 individuals with PD and 9 healthy controls. A force platform was used to measure the CoP displacement and velocity during the sit-to-standto-sit sequence. The results were statistically analysed.

Individuals with PD required greater durations for the sit-to-stand-to-sit sequence than the controls $(p<0.05)$. The anteroposterior and mediolateral CoP displacement were higher in the individuals with PD $(p<0.05)$. However, only the anteroposterior CoP velocity in the stand-to-sit phase $(p=0.006)$ was lower in the same individuals. Comparing the single- and dual-task conditions in both groups, the duration, the anteroposterior CoP displacement and velocity were higher in the dual-task condition $(p<0.05)$.

The individuals with PD presented reduced postural control stability during the sit-to-stand-to-sit sequence, especially when under the dual-task condition. These individuals have deficits not only in motor performance, but also in cognitive performance when performing the sit-to-stand-to-sit sequence in their daily life tasks. Moreover, both deficits tend to be intensified when two tasks are performed simultaneously.
\end{abstract}

\section{Keywords}

Dual-task; Parkinson's; Postural control; Sit-to-stand-to-sit

\section{Introduction}

Parkinson's disease (PD) is considered the second most common neurodegenerative disorder, affecting about $1 \%$ of the world's current population [1] and [2]. Some projections indicate a large increase of this prevalence over the coming decades [2]. 
At the moment, the aetiology is explained by genetic predisposition and the presence of toxic environmental factors [3] and [4]. The majority of individuals with PD present an inadequate interaction between systems responsible for body balance, including the vestibular, visual and proprioceptive systems. Consequently, these individuals tend to shift their centre of gravity forward, and therefore, have difficulty to perform compensatory movements to require balance [5]. The transition from sitting to standing and standing to sitting are components of some everyday functional tasks that are highly demanding from a postural control perspective. In fact, the sit-to-stand-to-sit (STSTS) sequence implies the involvement of anticipatory postural adjustments (APAs) to movement performance [6], [7] and [8]. Hence, the study concerning the STSTS sequence can contribute to clarify postural control requirements during daily activities. The variability and efficiency of functional movements require an appropriate postural control that depends on APAs to maintain stability of internal and external disturbances, taking into account the context and the task [9]. The planning of APAs involves various structures of the central nervous system (CNS), such as the pre-motor cortex, supplementary motor area, basal ganglia and cerebellum [10] and [11] that, through independent channels, convey information to the reticular formation, such as the pedunculopontine nucleus, which is important to modulate the APAs [12]. The neural connection between the basal ganglia and the pedunculopontine nucleus is through the corticostriatal-pallidumpedunculopontine circuit, which is compromised in individuals with PD leading to postural control deficits. This is manifested in the changes in the activation of postural muscles in the form of APAs [10], [13], [14] and [15]. As the CNS is responsible for the motor modulation circuits, which are compromised in individuals with PD, there is a decrease in postural control and consequently, repercussions in the performance of tasks, like STSTS sequences [16], [17] and [18]. This decreased postural control was demonstrated through CoP displacement variables. The CoP displacement reflects the orientation of body segments and corrective responses that control the centre of mass over the base of support [19], resulting from the combination of descending motor commands and the mechanical properties of the surrounding muscles [20]. In situations of dual-task, the use of cortical resources to perform motor tasks can affect or influence the performance of one or both tasks [21], [22] and [23]. Despite the importance of the postural control stability for the STSTS sequence performance and the impact of PD on the postural control system, few studies have assessed these issues and only the sit-to-stand sequence has been addressed. Additionally, no study has evaluated this task under high cognitive demanding conditions. Based on these facts, the objective of the present study 
was to analyse the postural control stability in individuals with PD in single- and dual-task conditions. More specifically, the postural stability was assessed through representative CoP displacement variables in the anteroposterior and mediolateral directions (displacements and velocities), in the five phases of the STSTS sequence in single- and dual-task conditions. Based on the results obtained by Bhatt et al. [16] and on the neural dysfunction involving postural control pathways, a reduced postural control stability in individuals with PD can be hypothesised during the preforming of the STSTS sequence. This reduced stability would be amplified in these individuals when the STSTS sequence is performed in the dual-task condition.

\section{Materials and methods}

\subsection{Study design and participants}

A cross-sectional study was implemented using a non-probabilistic [24] sample of 9 individuals with PD and 9 healthy controls, aged between 52 and 80 years old. The individuals diagnosed with PD were patients from the Parkinson's Association, Porto, in Portugal, while the healthy controls were communitydwelling volunteers, mainly from Porto.

Subjects were excluded if they presented one of the following criteria: severe cognitive impairment (screened using the Montreal Cognitive Assessment (MoCA) test [25]); incapable of performing the sit-to-stand or stand-to-sit sequence independently; and unable to speak. Severely disabled PD patients (> 3 Hoehn and Yahr scale [26]), patients diagnosed with any other neuromuscular disease, and those who had undergone deep brain stimulation through subthalamic surgery or were taking cholinergic medication were also excluded. Healthy controls that had been diagnosed as adults with any neuromuscular disorder or that could not be considered sedentary according to the Centre for Disease Control for the American College of Sports Medicine, were also excluded [27].

A trained researcher conducted the data collection based on a structured protocol. The study was approved by the Ethical Review Board of "Escola Superior de Tecnologia da Saúde - Instituto Politécnico do Porto", in Portugal. Written informed consent, according to the Helsinki Declaration, was obtained from all participants.

\subsection{Instruments}

The data collected from all participants included the sociodemographic characteristics age, gender, height, weight and level of education, and years of 
disease, cognitive performance (assessed using the MoCA test), Hoehn and Yahr scale and the CoP data acquired using a force platform (model FP4060-8 from Bertec Corporation (USA)) under the single- and dual-task conditions.

The scale of Hoehn \& Yahr (1967) evaluates the severity of overall dysfunction in individuals with PD. It is a 7-point scale, in which each point represents a different stage of the disease (stages 1-5, including 1.5 and 2.5). The scale increases with the severity of dysfunction along with the stage of the disease [26]. The MoCA test consists of eight fields: visuospatial, nomination, memory, attention, language, abstraction, deferred evocation and orientation. The performance of an individual is calculated by the addition of the scores obtained in each of the domains, and the maximum that can be reached is equal to 30 points [25] and [28].

For the evaluation of the postural control, the data from the force platform was acquired at a sampling rate of $1000 \mathrm{~Hz}$ [29]. The platform was connected to a Bertec AM 6300 amplifier (USA) and in turn, this was connected to an analogdigital converter from Biopac Systems, Inc. (USA), and to an analog board of Qualysis Track Manager (Sweden) that can be used for stabilometric analyses. The stabilometric measurements comprise the assessment of balance in the orthostatic position through body movements, taking into account the anteroposterior $(\mathrm{Fx})$, mediolateral $(\mathrm{Fy})$ and vertical $(\mathrm{Fz})$ components of the ground reaction force. For this, it is necessary to monitor the movement of the $\mathrm{CoP}$ in the anteroposterior (CoPAP) and mediolateral (CoPML) directions [30]. The signal related to the CoP movement was filtered using a fourth-order Butterworth low pass filter with a cut-off frequency of $20 \mathrm{~Hz}$ [31].

The attention level and consequently, the motor control perturbations were attained through a cognitive secondary task, namely the Stroop colour word test. This test consists in the enunciation of the visual colour instead of the written one. The number of errors and the number of named items were used for analysis [32] during a pre-defined time (60 s) for both groups.

\subsection{Procedures}

After an explanation of all the procedures involved, all individuals performed the study with shorts and standard shoes [33]. The height of the chair seat was adjusted to $100 \%$ of the lower leg length (from the knee joint to the ground), and $2 / 3$ of the femur supported on the seat was used as a reference for the subjects to be considered in the sitting position. In the single-task condition, the subjects were asked to rise from sitting with a self-selected speed without using their upper limbs [34], then remain for $60 \mathrm{~s}$ in the standing position, looking at a point two 
meters away at eye level. After this interval, subjects were instructed to sit, again without any kind of support and at a self-selected speed. In the dual-task condition, all the previous procedures were repeated; however, the subjects were required to perform the Stroop test during the performing of the STSTS sequence [28]. The test words in different colours were projected on a wall at eye level. The subjects were instructed to name the colour instead of reading the word and no other specific instructions were given. The words were present according to each participant's responses during a pre-defined period of $60 \mathrm{~s}$. A one minute rest between each trial was allowed, and the necessary repetitions were performed in order to obtain three valid trials for each subject.

The CoP displacement variables were analysed over the five phases of the STSTS sequence. For this, the sit-to-stand-to sit sequence was divided into five phases: sitting phase - phase 1, sit-to-stand phase - phase 2, standing phase phase 3, stand-to-sit phase - phase 4, and sitting phase - phase 5. The procedures used to identify the phases are shown in Table 1.

\begin{tabular}{|c|c|c|}
\hline & Start & End \\
\hline Phase 1 & $\begin{array}{l}\text { The instant when the CoP signal derived from the baseline (obtained in } \\
\text { the sitting position) was greater than } 3 \text { standard deviations for a } \\
\text { minimum interval of } 50 \mathrm{~ms} \text {. }\end{array}$ & $\begin{array}{l}\text { The instant associated to the first local maximum of the CoP signal from } \\
\text { the sit-to-stand sequence. }\end{array}$ \\
\hline Phase 2 & $\begin{array}{l}\text { The instant associated to the first local maximum of the CoP signal from } \\
\text { the sit-to-stand sequence. }\end{array}$ & $\begin{array}{l}\text { The instant of the first local minimum of the CoP signal during the } \\
\text { sit-to-stand sequence. }\end{array}$ \\
\hline Phase 3 & $\begin{array}{l}\text { The instant of the first local minimum of the CoP signal during the } \\
\text { sit-to-stand sequence. }\end{array}$ & $\begin{array}{l}\text { The instant when the CoP signal values were lower than the baseline } \\
\text { (obtained in the standing position) plus } 3 \text { standard deviations for a } \\
\text { minimum interval of } 50 \mathrm{~ms} \text {. }\end{array}$ \\
\hline Phase 4 & $\begin{array}{l}\text { The instant when the CoP signal derived from the baseline (obtained from } \\
\text { the standing position) was greater than } 3 \text { standard deviations for a } \\
\text { minimum interval of } 50 \mathrm{~ms} \text {. }\end{array}$ & $\begin{array}{l}\text { The instant associated to the first local maximum of the CoP signal from } \\
\text { the standing-to-sit sequence. }\end{array}$ \\
\hline Phase 5 & $\begin{array}{l}\text { The instant associated to the first local maximum of the CoP signal from } \\
\text { the standing-to-sit sequence. }\end{array}$ & $\begin{array}{l}\text { The instant when the CoP signal values were higher than the baseline } \\
\text { (obtained in the siting) plus } 3 \text { standard deviations for a minimum } \\
\text { interval of } 50 \mathrm{~ms} \text {. }\end{array}$ \\
\hline
\end{tabular}

Table 2

Comparison of the sociodemographic and anthropometric variables between the two groups under study.

\begin{tabular}{|c|c|c|c|}
\hline & $\begin{array}{l}\text { Individuals with } \mathrm{PD}(n=9) \\
\mathrm{M} \pm \mathrm{SD}\end{array}$ & $\begin{array}{l}\text { Healthy controls }(n=9) \\
M \pm S D\end{array}$ & p-Value \\
\hline Age [years] & $66.00 \pm 8.22$ & $63.89 \pm 8.09$ & $0.340^{*}$ \\
\hline Gender (male), $n(\%)$ & $6(66.7)$ & $4(44.4)$ & $0.319^{* *}$ \\
\hline Education [years] & $7.67 \pm 5.07$ & $7.78 \pm 4.58$ & $0.796^{*}$ \\
\hline Weight $[\mathrm{Kg}]$ & $69.33 \pm 12.59$ & $74.00 \pm 9.86$ & $0.796^{*}$ \\
\hline Height [m] & $1.65 \pm 0.08$ & $1.64 \pm 0.08$ & $0.931^{*}$ \\
\hline $\mathrm{MoCA}$ & $24.44 \pm 2.24$ & $26.33 \pm 1.00$ & $0.063^{*}$ \\
\hline \multicolumn{4}{|l|}{ Hoehn and Yahr scale } \\
\hline Stage $1, n(\%)$ & $3(33.3)$ & - & - \\
\hline Stage $1.5, n(\%)$ & $3(33.3)$ & - & - \\
\hline Stage $2, n(\%)$ & $1(11.1)$ & - & - \\
\hline Stage $2.5, n(\%)$ & $2(22.2)$ & - & - \\
\hline Years of PD & $10.22 \pm 5.38$ & - & - \\
\hline Stroop test ( $\mathrm{N}^{*}$ of naming colours) & $30.89 \pm 11.19$ & $35.611 \pm 17.099$ & $0.489^{*}$ \\
\hline
\end{tabular}

Hoehn and Yahr scale: Stage 1 - Unilateral disease; Stage 1.5 - Unilateral and axial disease; Stage 2 - Bilateral disease without impairment of balance; Stage 2.5 - Mild bilateral disease; Stage 3 - Mild to moderate bilateral disease.

"Independent samples $t$-test and " chi-square test.

The data acquisition was always performed by the same investigator to ensure the reproducibility of the procedures. The data analysis was performed using the 
Matlab software (MathWorks, USA) and Acqknowledge software (Biopac Systems, Inc. USA).

\subsection{Statistical analysis}

Descriptive statistical analyses were performed using proportions and measures of central tendency and dispersion.

The independent sample $t$ test and Chi square test were performed to examine whether there were significant differences between the groups in terms of the sociodemographic and anthropometric variables. The multiple analysis of variance (MANOVA) test was used to analyse the interaction between the groups (PD and controls) and the conditions (single- and dual-task). The Bonferroni analysis was used as a post-hoc test to determine the differences in single- and dual- task conditions in each group and to determine for each condition the differences between the groups (PD and controls). The number of errors and the number of correctly named items for the Stroop test were used as covariates in the analysis. Two-tailed tests were used in all analyses, and $\mathrm{p}<0.05$ was adopted for statistical significance. All statistical analyses were conducted using IBM SPSS Statistics 22.0 (SPSS, Inc., Chicago, IL, USA).

\section{Results}

The 9 PD individuals $(66.7 \%$ male) had a mean age of 66 years old (standard deviation $(S D)=8.2$, a mean education of 7.7 years $(S D=5.6)$ and a mean number of years with PD $10.22(S D=5.38)$. Most of these participants were classified in stage 1 and 1.5 of the Hoehn and Yahr scale. The 9 healthy controls $(44.4 \%$ male) had a mean age of 63.9 years $(S D=8.1)$ and a mean education of 7.8 years $(S D=4.6)$. The Mann-Whitney test and chi-square test showed no significant differences between the two groups studied, Table 2 .

The MANOVA test showed that in phase 1, no significant differences were found between the groups (between-subjects) or conditions (within-subjects) and also no significant interaction was found between group and condition, Table 3 . 


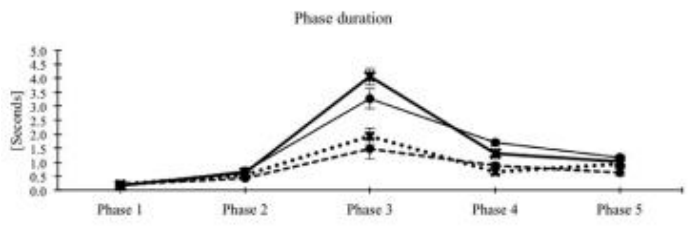

$\longrightarrow$ ST: Individuals with PD

$\longrightarrow$ DT: Individuals with PD

$\cdots \cdot$ ST: Healthy controls

$-\bullet--D T$ : Healthy controls
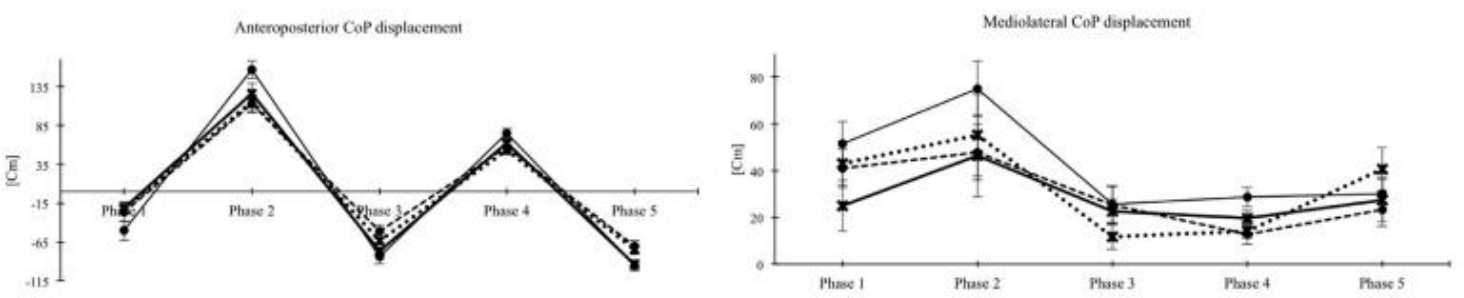

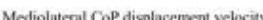
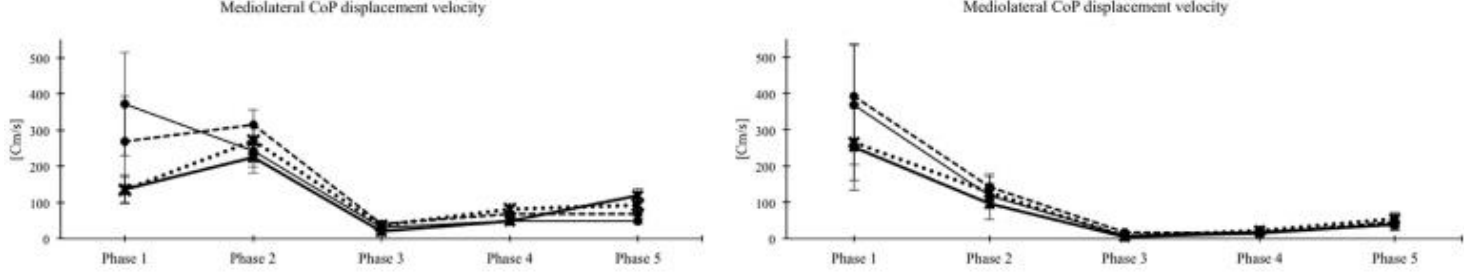

Fig. 1. Estimated marginal means and standard error of the phase durations and CoP based parameters under the single-and dual-task conditions for both groups.

Table 3

Results of the MANOVA test with p-Values of between-subjects, within-subjects and interaction for the duration of each phase and $\mathrm{CoP}$ based parameters.

\begin{tabular}{|c|c|c|c|c|c|c|}
\hline \multirow[b]{2}{*}{ Phase } & & \multicolumn{5}{|c|}{ Covariates adjusted - p-Values } \\
\hline & & Duration & CoPAP & CoPML & VelAP & VelML \\
\hline \multirow[t]{3}{*}{1} & Group (between-subject) & 0.267 & 0.276 & 0.725 & 0.662 & 0.909 \\
\hline & Group (within-subjects) & 0.348 & 0.640 & 0.817 & 0.765 & 0.943 \\
\hline & Interaction & 0.712 & 0.210 & 0.145 & 0.513 & 0.959 \\
\hline \multirow[t]{3}{*}{2} & Group (between-subject) & $<0.05$ & 0.088 & 0.606 & 0.238 & 0.496 \\
\hline & Group (within-subjects) & 0.149 & 0.623 & 0.787 & 0.408 & 0.986 \\
\hline & Interaction & 0.092 & 0.120 & 0.167 & 0.737 & 0.932 \\
\hline \multirow[t]{3}{*}{3} & Group (between-subject) & $<0.01$ & $<0.05$ & 0.449 & 0.062 & 0.054 \\
\hline & Group (within-subjects) & 0.354 & 0.271 & 0.625 & 0.885 & 0.150 \\
\hline & Interaction & 0.606 & 0.137 & 0.410 & 0.614 & 0.089 \\
\hline \multirow[t]{3}{*}{4} & Group (between-subject) & $<0.01$ & 0.056 & $<0.05$ & $<0.01$ & 0.844 \\
\hline & Group (within-subjects) & $<0.01$ & 0.740 & 0.325 & 0.822 & 0.071 \\
\hline & Interaction & 0.333 & 0.499 & 0.069 & 0.493 & 0.108 \\
\hline \multirow[t]{3}{*}{5} & Group (between-subject) & 0.173 & $<0.05$ & 0.734 & 0.077 & 0.590 \\
\hline & Group (within-subjects) & 0.587 & $<0.05$ & 0.074 & $<0.01$ & 0.284 \\
\hline & Interaction & $<0.05$ & 0.369 & 0.125 & $<0.01$ & 0.795 \\
\hline
\end{tabular}

In phase 2, a significant difference between the groups was found. The individuals with PD presented a greater duration $(p=0.047)$ compared to the healthy controls. The Post-hoc analysis showed that these differences occurred only in the dual-task condition $(p=0.005)$. However, no differences between conditions or any significant interaction between groups and conditions were found.

In phase 3, the differences between groups were found in terms of the duration and CoPAP displacement. The duration was significantly greater in the PD individuals than in the healthy controls $(p<0.001)$. These differences occurred both under single- $(p<0.001)$ and dual-task $(p=0.004)$ conditions. The CoPAP displacement was significantly higher in the individuals with PD in comparison to 
the healthy controls (0.015). The Post-hoc analysis showed that these differences occurred under the dual-task condition $(p=0.021)$. No differences between the tasks or any significant interaction between group and condition were found.

In phase 4, the differences between the two groups occurred in the duration, CoPML displacement and CoPAP velocity. The duration was significantly greater in the individuals with PD than in the healthy controls $(p<0.001)$. Relative to the healthy controls, the CoPML displacement was significantly higher $(p=0.036)$ and the CoPAP velocity was significantly lower $(p=0.006)$ in the individuals with PD. The Post-hoc analysis showed that these differences occurred both under the single and dual-task conditions, except in terms of the CoPML displacement that occurred only in the dual-task condition $(p=0.015)$. Also, differences between the two conditions were found in the duration, with a longer duration in the dual- than in the single-task condition $(p=0.009)$. The Post-hoc analysis showed that these differences occurred in the group with $\operatorname{PD}(p=0.004)$. Finally, no significant interaction between group and condition were found.

In phase 5 , only the COPAP displacement had differences between the two groups, with higher values for the individuals with PD in comparison to the healthy controls. However, significant differences were found between the conditions for the CoPAP displacement $(p=0.043)$ and velocity $(0.010)$, with higher values for the dual-task condition. Also, no significant interaction between group and condition was found in terms of the duration and CoPAP velocity, which seems to indicate that the differences in the duration and CoPAP velocity were caused by the disease (PD).

The estimated marginal means of the conditions and groups is presented in Fig. 1.

\section{Discussion}

This study reveals significant differences regarding the postural control of individuals with PD. It is clear that there is a relationship between performing the STSTS sequence and performing a cognitive task.

Comparing the individuals with PD and the healthy controls studied as to the duration of each phase of the sit-to-stand-to-sit sequence, significant differences were found in the single- and dual-task conditions in phases $2-4$. This finding corroborates previous studies that show a significant increase in the duration of the phases of the STSTS sequence performed by individuals with PD [16]. No difference in the duration of phase 1 was found in the study of Inkster [35], where the time to rise from a chair was not significantly different between individuals with PD (ON medication) and controls. The differences found in the duration of phases 2-4 between the two groups in both the single- and dual-task conditions 
can be explained by the pathophysiology of PD. In phase 2, the individuals have to perform a sit-to-stand transfer and the greater duration of this transition in PD individuals compared to healthy controls could be due to the bradykinesia and rigidity present in individuals with PD. Phase 3 corresponds to a stabilization phase that rarely presents any postural deficits in PD. In phase 4, individuals have to control the postural muscles, including the soleus eccentric activity, which is a complex task for individuals with PD [14] and [15].

Comparing the CoPAP and CoPML displacements between the individuals with PD and the healthy controls, significant differences were only found in the dualtask condition, with the former group showing higher CoPAP displacements and a weaker relation for the CoPML displacement. Individuals with PD have superior backward stability resulting from a more anterior CoP position at seat-off [16]. Given these differences in movement patterns, individuals with mild to moderate severity of PD have an exaggerated anticipatory response in the preparation phase in comparison to individuals without PD. This anticipatory response is manifested as an increased momentum that generates a greater forward CoP displacement [35]. Furthermore, several studies have shown an altered function of the supplementary motor area in individuals with PD due to its indirect connections with the basal ganglia [36].

Compared to the healthy controls, the individuals with PD had a lower CoPAP velocity in the single-task condition in phases 3 and 4 , and also a lower CoPML velocity in phase 3. During the STSTS sequences, these individuals demonstrated a large proportion of co-contraction because they move slower [37]. However, individuals with PD compensate their slowness and related posterior instability by positioning their CoP forward at seat-off [38]. The lower velocity could increase the likelihood of backward balance loss at seat-off because of its proximity to their limits of stability [39].

Comparing the single- and dual-task conditions, only significant differences were found in the CoPML velocity in phase 3 . The few differences between the singleand dual-task conditions in individuals with PD may be due to the time of diagnosis of the PD of the individuals studied (10.22 \pm 5.38 years), as they may have already acquired, over time, several strategies that assist in carrying out daily life tasks, such as the movements required during the STSTS sequence. These strategies can also justify the similarity with some findings obtained for healthy controls [40], as well as, the fact that the PD group only had a mild severity of the disease (median Hoehn \& Yahr score of 1.5). However, a limitation of this study is that the groups did not perform the cognitive task (Stroop test) in the single-task condition. The priority of a task is closely related to several factors such as: the progression stage of the disease, complexity of the secondary task, 
limitation of attentional resources, motivational preference, internal vs. external attention, and postural confidence [22], [41] and [42]. So the assessment using the Stroop test in the single-task condition could be helpful to determine the differences between the two groups at baseline. However, there are studies aimed to identify a number of factors in order to predict the Stroop performance. For example, one study found an inverse relationship between cognitive deficits and an increase of errors and therefore reduced the number of colours specified in the Stroop test [43]. Other studies have found that the level of education is also a predictor for the Stroop performance [44]. However, in this study, the cognitive impairment and educational level were taken into account. Individuals with cognitive impairment were not included in this study and there were no differences between the PD group and the healthy controls in terms of the performance of the MoCA test and of the educational level. Thus, although the Stroop test was not performed at baseline, it seems that the differences found in the dual-task condition are due to the introduction of the motor task. Nevertheless, this should be confirmed in future studies.

In this study, we found that the individuals with PD had greater difficulty in the stand-to-sit sequence, which has been ignored in current studies, than in the sitto-stand sequence, especially in the dual-task condition. Biomechanical studies focusing on posture stability have shown that the performance of dual-task has a significant effect on the postural control in these individuals [45], [46], [47] and [48]. This suggests that they create a restriction on APAs in order to focus on the cognitive task without losing the balance [22], [49] and [50]. Furthermore, recent studies with rehabilitative intervention in individuals with PD have shown promising results. The reported results indicate a potential for reversing or slowing the progression of the disease, demonstrating that the ability to learn is relatively well preserved [51]. Several studies have shown that the dual-task cognitive-motor training has a positive effect on gait in the PD population; in particular, in terms of the gait speed, variability and step length [52] and [53].

\section{Conclusion}

The individuals with PD presented reduced postural stability for most of the phases of the STSTS sequence, and this stability was most impaired in the dualtask condition. These findings may suggest that this postural control deficit could lead to compensatory motor strategies in the lower extremities. However, further studies concerning the impact of reduced stability during the STSTS sequence in individuals with PD and their compensatory motor strategies are required. 
This study also provides data and guidelines for future research, as well as pointing out the importance of cognitive training. Based on our findings that are in-line with the ones reported by other authors [54], [55] and [56], it is expected that the stimulation of the cognition can help achieve improvements in terms of motor task performance.

\section{Conflict of interest statement}

The authors report no conflict of interest.

\section{Competing interests}

None declared.

\section{Funding}

None.

\section{Ethical approval}

This study was approved by the Ethical Review Board of "Escola Superior de Tecnologia da Saúde - Instituto Politécnico do Porto", in Portugal.

\section{Acknowledgements}

This research was carried out with the support and contribution of the first Author's Ph.d grant from "Instituto Politécnico do Porto and Escola Superior de Tecnologia da Saúde", in Portugal.

\section{References}

[1]

P. Andlin-Sobocki, B. Jonsson, H. Wittchen, J. Olesen

Cost of disorders of the brain in Europe

Eur J Neurol, 12 (1) (2005), pp. 1-27

[2]

S. Campenhausen, B. Bornschein, R. Wick, K. Botzel, C. Sampaio, W. Poewe Prevalence and incidence of Parkinson's disease in Europe

Eur Neuropsychopharmacol, 15 (4) (2005), pp. 473-490 
[3]

G. Levy, E.D. Louis, L. Cote, M. Perez, H. Mejia-Santana, H. Andrews, et al.

Contribution of aging to the severity of different motor signs in Parkinson disease

Arch Neurol, 62 (3) (2005), pp. 467-472

[4]

Z. Huang, R. Fuente-Fernández, A.J. Stoessl

Etiology of Parkinson's Disease

Can J Neurol Sci, 30 (1) (2003), pp. 10-18

[5]

N. Smania, A. Picelli, C. Geroin, P. lanes, E.L. Marchina, A. Zenorini, et al.

Balance and Gait rehabilitation in patients with Parkinson's disease

Neurorehabilitation and Neural Repair J, 24 (9) (2010), pp. 826-834

[6]

W.G.M. Janssen, H.B.J. Bussmann, H.J. Stam

Determinants of the sit-to-stand movement: a review

Phys Ther, 82 (9) (2002), pp. 866-879

[7]

R.P. Duncan, A.L. Leddy, G.M. Earhart

Five times sit-to-stand test performance in Parkinson's disease

Arch Phys Med Rehabil, 92 (9) (2011), pp. 1431-1436

[8]

C. Mazza, M. Zokb, U.D. Croce

Sequencing sit-to-stand and upright posture for mobility limitation assessment: determination of the timing of the task phases from force platform data

Gait Posture, 21 (4) (2005), pp. 425-431 
[9]

A.S. Aruin

The organization of anticipatory postural adjustments

J Autom Control, 12 (1) (2002), pp. 31-37

[10]

J.V. Jacobs, J.S. Lou, J.A. Kraakevik, F.B. Horak

The supplementary motor area contributes to the timing of the anticipatory postural adjustment during step initiation in participants with and without Parkinson's disease

Neuroscience, 164 (2) (2009), pp. 877-885

D. Timmann, F. Horak

Perturbed step initiation in cerebellar subjects: 2. Modification of anticipatory postural adjustments

Exp Brain Res., 141 (1) (2001), pp. 110-120

[12]

B. Schepens, T. Drew

Independent and convergent signals from the pontomedullary reticular formation contribute to the control of posture and movement during reaching in the cat

J Neurophysiol, 92 (4) (2004), pp. 2217-2238

[13]

D. Purves, G. Augustine, D. Fitzpatrick, W. Hall, A. Sanuellamantia, J. Mcnamara, et al.

Neurocience

(3 ed.)Sunderland, U.S.A. (2004)

[14]

Shumway-Cook, M.H. Woollacott

Motor Control: Translating Research Into Clinical Practice 
Wolters Kluwer Health (2007)

[15]

C. Karachi, D. Grabli, F.A. Bernard, D. Tandé, N. Wattiez, H. Belaid, et al.

Cholinergic mesencephalic neurons are involved in gait and postural disorders in Parkinson Disease

J Clin Investig., 120 (8) (2010), pp. 2745-2754

T. Bhatt, F. Yang, M.K.Y. Mak, C.-Y. Hui-Chan, Y.-C. Pai

Effect of externally cued training on dynamic stability control during the sit-tostand task in people with Parkinson disease

J Am Phys Ther Assoc, 93 (4) (2013), pp. 492-503

[17]

S. O'Shea, M.E. Morris, R. lansek

Dual task interference during gait in people with Parkinson disease: effects of motor versus cognitive secondary tasks

Phys Ther, 82 (9) (2002), pp. 888-897

Tsukahara, R. Kawanishi, Y. Hasegawa, Y. Sankai

Sit-to-stand and stand-to-sit transfer support for complete paraplegic patients with robot suit HAL

Adv Robot, 24 (11) (2010), pp. 1615-1638

[19]

T. Prieto, J. Myklebust, R. Hoffmann, E. Lovett, B. Myklebust

Measures of postural steadiness: differences between healthy young and elderly adults

Biomed Eng (NY), 43 (9) (1996), pp. 956-966

L. Baratto, P. Morasso, G. Spada 
A new look at posturographic analysis in the clinical context: sway-density versus other parameterization techniques

Motor Control, 6 (3) (2002), pp. 246-270

[21]

T. Wu, M. Hallett

Dual task interference in Parkinson's disease

US Neurol (2009)

[22]

J. Holmes, M. Jenkins, A. Johnson, S. Adams, S. Spaulding

Dual-task interference: the effects of verbal cognitive tasks on upright postural stability in Parkinson's disease

Parkinsons Dis, 69 (6) (2010), pp. 49-52

[23]

V. Kelly, A. Eusterbrock, A. Shumway-Cook

The effects of instructions on dual-task walking and cognitive task performance in people with Parkinson's disease

Parkinson's Dis, 2012 (2012), pp. 1-9

J.W. Creswell, V.L.P. Clark

Designing and Conducting: Mixed Methods Research

(2 ed.)SAGE Publications, USA (2011)

[25]

S. Hoops, S. Nazem, A.D. Siderowf, J.E. Duda, S.X. Xie, M.B. Stern, et al.

Validity of the MoCA and MMSE in the detection of $\mathrm{MCl}$ and dementia in Parkinson disease

Neurology, 73 (21) (2009), pp. 1738-1745 
[26]

M.M. Hoehn, M.D. Yahr

Parkinsonism: onset, progression and mortality

Neurology, 17 (5) (1967), pp. 427-442

[27]

W. Thompson

ACSM's Guidelines for Exercise Testing and Prescription

(8 ed.)Lippincott: Williams \& Williams (2001)

[28]

A.J. Romann, S. Dornelles, N. Maineri, C.R.d.M. Rieder, M.R. Olchik

Cognitive assessment instruments in Parkinson's disease patients undergoing deep brain stimulation

Dement Neuropsychol, 6 (1) (2012), pp. 2-11

[29]

Hanke, W. Rogers

Reliability of ground reaction force measurements during dynamic transitions from bipedal to single-limb stance in healthy adults

Phys Ther, 72 (11) (1992), pp. 810-816

[30]

Geurts, B. Nienhuis, T. Mulder

Intrasubject variability of selected force-platform parameters in the quantification of postural control

Arch Phys Med Rehabil, 74 (11) (1993), pp. 1144-1150

M. Schmid, S. Confortoemail, V. Camomilla, A. Cappozzo, T. D'Alessio

The sensitivity of posturographic parameters to acquisition settings

Med Eng Phys, 24 (9) (2002), pp. 623-631 
[32]

M.D. Lezak, D.B. Howieson, D.W. Loring

Neuropsychological Assessment

(4 ed.)Oxford University Press, New York (2004) Incorporated

[33]

M. Kim, C. Yi, W. Yoo, B. Choi

EMG and Kinematics analysis of the trunk and lower extremity during sit-tostand task while wearing shoes with different heel heights in healthy young women

Hum Mov Sci, 30 (3) (2011), pp. 596-605

V. Dubost, O. Beauchet, P. Manckoundia, F. Herrmann, F. Mourey

Decreased trunk angular displacement during sitting down: an early feature of aging

Phys Ther, 85 (5) (2005), pp. 404-412

L.M. Inkster, J.J. Eng

Postural control during a sit-to-stand task in individuals with mild Parkinson's disease

Exp Brain Res, 154 (1) (2004), pp. 33-38

[36]

R. Cunnington, R. lansek, G.W. Thickbroom, B.A. Laing, F.L. Mastaglia, J.L. Bradshaw, et al.

Effects of magnetic stimulation over supplementary motor area on movement in Parkinson's disease

Brain Cogn, 119 (Pt 3) (1996), pp. 815-822

L.A.P.S. Souza, M.B. Curtarelli, M. Mukherjee, VC. Dionisio 
The effect of the partially restricted sit-to-stand task on biomechanical variables in subjects with and without Parkinson's disease

J Electromyogr Kinesiol, 21 (5) (2011), pp. 719-726

[38]

M. Mancini, L. Rocchi, F.B. Horak, L. Chiari

Effects of Parkinson's disease and levodopa on functional limits of stability

Clin Biomech, 23 (4) (2008), pp. 450-458

Y.C. Pai, W.A. Lee

Effect of a terminal constraint on control of balance during sit-to-stand J Mot Behav, 26 (3) (1994), pp. 247-256

[40]

G. Wulf, M. Landers, R. Leithwaite, T. Tollner

External focus instructions reduce postural instability in individuals with Parkinson disease

Phys Ther, 89 (2009), pp. 162-168

V.E. Kelly, A.J. Eusterbrock, A. Shumway-Cook

A review of dual-task walking deficits in people with Parkinson's disease: motor and cognitive contributions, mechanisms, and clinical implications

Parkinson's Dis, 2012 (918719) (2012), pp. 1-14

[42]

S. Schaefer

The ecological approach to cognitive-motor dual-tasking: findings on the effects of expertise and age

Front Psychol, 5 (1167) (2014), pp. 1-9 
[43]

W. Van der Elst, M. Van Boxtel, G. Van Breukelen, J. Jolles

The stroop color-word test influence of age, sex, and education; and normative data for a large sample across the adult age range

Assessment, 13 (1) (2006), pp. 62-79

[44]

R.J. Ivnik, J.F. Malec, G.E. Smith, E.G. Tangalos, RC. Petersen

Neuropsychological tests' norms above age 55: COWAT, BNT, MAE, Token, WRAT-R reading, AMNART, STROOP, TMT, and JLO

Clin Neuropsychol, 10 (3) (1996), pp. 262-278

[45]

R. Fama, E. Sullivan

Motor sequencing in Parkinson's disease: relationship to executive function and motor rigidity

Cortex, 38 (5) (2002), pp. 753-767

[46]

S. Springer, N. Giladi, C. Peretz, G. Yogev, E. Simon, J. Hausdorff

Dual-tasking effects on gait variability: the role of aging, falls, and executive functions

Mov Disord, 21 (7) (2006), pp. 950-957

[47]

B. Van-Lersel, P. Kessels, R. Bloem, A. Verbeek, M. Rikkert

Executive functions are associated with gait and balance in community-living elderly people

J Gerontol Ser A Biol Sci Med Sci, 63 (12) (2008), pp. 1344-1349 
[48]

Coppin, A. Shumway-Cook, J. Saczynski, K. Patel, A. Ble, L. Ferrucci

Association of executive function and performance of dual-task physical tests among older adults: analyses from the InChianti study

Age Ageing, 35 (6) (2006), pp. 619-624

[49]

J.R. Nocera, R. Roemmich, J. Elrod, L.J.P. Altmann, C.J. Hass

Effects of cognitive task on gait initiation in Parkinson disease: evidence of motor prioritization?

J Rehabil Res Dev., 50 (5) (2013), pp. 699-708

[50]

R. Marchese, M. Bove, G. Abbruzzese

Effect of cognitive and motor tasks on postural stability in Parkinson's disease: a posturographic study

Mov Disord, 18 (6) (2003), pp. 652-658

[51]

S. Chiviacowsky, G. Wulf, R. Lewthwaite, T. Campos

Motor learning benefits of self-controlled practice in persons with Parkinson's disease

Gait Posture, 35 (4) (2012), pp. 601-605

[52]

G. Yogev-Seligmann, N. Giladi, M. Brozgol, J. Hausdorff

A training program to improve gait while dual tasking in patients with Parkinson's disease: a pilot study

Archive Phys Med Rehabil, 20 (2011), pp. 176-181 
[53]

V. Sethi, R. Raja

Effects of Dual task training on balance and activities of Daily Livings (ADLs)

in patients with Parkinsonism

Int J Biol Med Res, 3 (3) (2012), pp. 1359-1364

[54]

S.G. Brauer, M. Woollacott, R. Lamont, S. Clewett, J. O'Sullivan, P. Silburn

Single and dual task gait training in people with Parkinson's disease: a protocol for a randomised controlled trial

BMC Neurol, 11 (90) (2011), pp. 1-6

[55]

M. Hiyamizu, S. Morioka, K. Shomoto, T. Shimada

Effects of dual task balance training on dual task performance in elderly people: a randomized controlled trial

Clin Rehabil, 26 (1) (2011), pp. 58-67

[56]

S. Vanshika, R. Ravi

Effects of Dual task training on balance and activities of Daily Livings (ADLs) in patients with Parkinsonism

Int J Biol Med Res, 3 (1) (2012), pp. 1359-1364 